\title{
The Effects of Gender and Body Mass Index to Body Image
}

\author{
Mary Rachelle R Wapaño, PhD \\ Kinaadman Research Center, Xavier University - Ateneo de Cagayan, Philippines
}

\begin{abstract}
This study is investigated how the body image of adolescents is affected by gender and body mass index and the interaction of both. The respondents of this study were 60 College freshmen undergraduate students. Convenience sampling was used in this study to get a preliminary gross estimate of results. Judgment sampling was also used in this study. To investigate the effects of gender and body mass and their interaction effects to body image, two-way analysis of variance was used. The results of this study supported the hypothesis that gender has an effect on body image regardless of body mass index. The resultsdid not support the hypotheses that body mass index has a significant effect on body image regardless of gender as well as the effect of gender on body image depends on body mass index.
\end{abstract}

It is suggested that other anthropomorphic measures may be used, gender differences in body image also be further examined

Keywords: gender, body mass index, body image

\section{INTRODUCTION}

B ody image involves an individual's perception, imagination, emotions, and physical sensations of and about one's body and thought to be a basic component of selfconcept or identity. In 1950, Schilder (as cited in Grogan, 2016, p. 11) defined body image as "the picture of our own body which we form in our mind." He contended that body image is a perceptual construct; that is one's perceived body size, and feelings of lightness or heaviness. He continued to argue that body image is also a reflection of attitudes and interactions with others. After the Schilder's 1950 definition, the term "body image" moved beyond the perceptual construct definition, and began to focus on weight satisfaction, size perception accuracy, appearance orientation, body concern, body esteem, body schema, body appreciation. From then on, body image was re-defined as "a person's perceptions, thoughts, and feelings about his or her body (Grogan, 2016). This definition includes perception and attitudes towards the body as well as positive and negative aspectes of body image.

In this study, body image is conceptualized as a multidimensional construct that represents how one thinks, feels, and behaves about his/her physical qualities (Muth \& Cash, 1997). Body image is thought to have two components: body image evaluation and body image investment. Cash \& Szymanski (1995) proposed that body-image evaluation component involves an individual's perception and evaluation about his/her physical appearance. The second component, body-image investment, refers to the behaviors individuals perform to manage and improve their physical appearance.

For adolescents, body image is an important aspect of selfrepresentation. Morrison, Kalin, \& Morrison (2004) study suggests that, male and female adolescents engage in social comparison and is a significant predictor of body image evaluation and body image investment. Studies have shown gender differences of body dissatisgaction among adolescents.

For example, adolescent girls reported increased level of body dissatisfaction compared to their male counterparts (Rosenbaum \& Lewis, 1999; Ludden \& Laily, 2007). The same study showed that body dissatisfaction among adolescents appear to be weakly related to their body mass index, and other people's perceptions of adolescents' physical attractiveness. However, when adolescents have developed a body image, this may remain constant through adolescence. Body image, can then be considered as an important aspect of self-representation and self-evaluation during adolescence.

Although body image is a multidimensional construct, it is most frequently defined as the degree of satisfaction with one's current physical self which includes size, shape, general appearance (Cash \& Deagle, 1997). There are many sources of body image: including self-observation, responses of others, and the exposure in media regarding societal ideals of physical attractiveness. Additionally, other related studies on body image indicate that body dissatisfaction and self-esteem are strongly related (Berg, Mond, Eisenberg, Ackard, Sztainer, 2010). This result suggests the importance of addressing adolescents' issues that relate to body image.

Davison and McCabe (2006) revealed that adolescent females tended to report a more negative body image than their male counterparts; and that for males and females, the relevance of body image to self-esteem is similar. Moreover, female appear to be more concerned about others' opinion of their bodies and is important in understanding their self-esteem

Society places heavy emphasis on body weight, size and appearance. People are conditioned at an early stage that selfworth is derived from these external characteristics. It appears that physical characteristics are associated with certain traits such as: beingthin or muscular are believed to be "hardworking, successful, popular, and self-disciplined," while being fat is associated with being "lazy, ignorant, hated, ugly, weak, and lacking will-power." While this is prevalent in the society, media, one's peers and well-meaning parents 
and health professionals reinforce it. It seems then that adolescents feel anxiety and pressure to achieve and maintain a very lean physique. The media sets unrealistic standards for what body weight and appearance is considered "normal." Girls are conditioned at a very young age that Barbie is how a woman is supposed to look, that is, huge breasts with no fat. Similarly, boys are given the impression that men naturally have muscles bulging all over their bodies. With these media body ideals, men and women feel tend to feel ashamed, inadequate and dissatisfied with their bodies. Brumberg (1997) reported that at age thirteen, 53 percent of American girls are "unhappy with their bodies, this grows to 57 percent when they reach seventeen. The study of Harrison \& Cantor (1997) showed that media exposure is positively related to striving for thinness for men and body dissatisfaction among women. Hargreaves (2002) also showed that teen-age girls who viewed commercials depicting women with the thin-ideal type of beauty caused adolescent girls to feel less confident, angrier and more dissatisfied with their weight and appearance.

Voelker, Reel, and Greenleaf (2015) say that adolescence is a critical stage in the development of body image. Many factors influence adolescent body image, such as weight, the media, and peers. Adolescents tend to internalize the norms set by the media, and to feel pressured to conform to socially prescribed body ideals.

This study thenis an attempt to investigate how the body image of adolescents is affected by gender and body mass index and the interaction of both.

Body image can be thought of as self-schema (Altabe\& Thompson, 1996). In general, self-schemas are memory structures that incorporate knowledge about the self in specific content areas that reflect particular importance, expertise, and meaningfulness to the person. These mental representations of the self are stored in long-term memory and are hierarchically organized. Self-schemas can be developed about any part of the person, including physical characteristics (thin or fat), social roles (mother, friend, student), personality traits (reserved, outgoing), and areas of particular interest and skill (singer or dancer). Because of the rich array of information encoded in the self-schema and its repeated activation, self-schemas are traditionally believed to be stable, enduring structures that are chronically accessible in working memory.

Body image as a schema is an internalized perception of one's physical appearance that shapes behavior and thinking. Body image as self-schema is a person's internalized view of his/her physical appearance that, in turn, directs his/her behavior and influences his/her thinking. Self-schema theory considers the body as mental construction than an objective evaluation. Body image then is a self-representation developed over time as a reaction to the experience of being labeled in a specific way by others.
Body image dissatisfaction among adolescents may be explained by social comparison theory. Social comparison theory was first advanced by social psychologist Leon Festinger in 1954 (as cited in Suls\& Wheeler, 2013): He proposed that individualsare driven to gain accurate selfevaluations by evaluating own abilities in comparison to others.

Social comparsion has been believed to be central to the development of body image. It refers to intrinsic, cognitive evaluations that people make about their own physical attributes relative to others. The comparisons seem to be more subjective than objective in that it does not depend unbiased measures but on personal standards on certain attributes. In principle, individuals prefer to compare themselves to similar others, e.g. similar level of physical attractiveness.

Research has established that there is a relationship between body image and social comparison, more so for women than for men. The findings reveal that women who tend to engage in social comparison are likely to be more dissatisfied with their body image. This negative relationship is explained when the target for appearance comparisons were models and celebrities presented by media. Thin female and muscular male models are idealized in the media.

Social comparison to these idealized images promote discrepancy between self-evaluation of physical appearance and the idealized standard of physical attractiveness, in turn leading to more negative body image (Cusumano \& Thompson, 1997; Spitzer, Henderson, \& Zivian, 1999).

Among college women, comparing one's physical attributes to individuals considered to be more attractive is reportedly common. This upward comparison of physical attributes has been shown to be related to increased body dissatisfaction among college women Pinkasavage, Arigo,., \& Schumacher, 2015).

Jones (2001) showed that male and female adolescents compare their weight to both their peers and model targets and was found to be related to body dissatisfaction. For females, shape comparisons are found to be also related to body dissatisfaction

Studies on body image have also revealed gender differences. Studies by Fallon and Rozin (1985) showed that both males and females have consistently expressed and experienced much displeasure over their body shapes. Their results showed that females showed a greater dissatisfaction with their present body shape in relation to their perception of men's ideal figure preference. Other studies (Cohn and Adler, 1992) found similar results. They showed that there is tremendous pressure placed on women to seek the ideal body shape. Many other studies support this result: females are significantly more affected than men by their distorted body image. Research has shown that women typically wantto be thinner than their present size, and tend to overestimate the attractiveness of thin women to men. On the other hand, men 
who are dissatisfied with their appearance often want to be heavier than their present size, and they, too, overestimate the attractiveness of larger, more muscular men to women. The prevalence of body dissatisfaction among men and women is supported by Garner, Garfinkel, Schwartz and Thompson (1980)who reported that socio-cultural perception of thinness and how females perceive thinness in the United States has changed over the last quarter century, but it seems to have intensified, that is, the ideal body has become increasingly thinner. Recent studies supported gender difference in body image. The study of Fisher, Dunn, \&Thompson (2002) revealed that in comparing oneself to others, individuals appear to use two primary comparison dimensions, weight/non-weight and muscle/non-muscle and those males and females differ significantly in comparison schemas along these two dimensions. Females tended to emphasize the weight/non-weight continuum whereas males tended to emphasize the muscle/non-muscle dimension. The same study showed that the same comparison schemas were used by both younger (7th graders) adolescents and older adolescents (college students) (Fisher, Dunn, \&Thompson, 2002).

Studies have shown that BMI may be an important factor in identifying potential body image disorders in college-aged men (Watckins et al. 2008). Body Mass Index (BMI) is a measure of body mass ranging from thinness to adiposity.

The results showed that BMI was significantly correlated with negative body image. Overweight and obese participants reported significantly higher levels of negative body image then their normal and underweight counterparts. Overweight respondents also reported significantly higher weight and shape issues that did the underweight, normal and obese respondents. The non-normal weight participants, i.e. underweight, overweight and obese participants reported significantly higher levels of body dissatisfaction than their normal-weight counterparts.

Research by Burger (2002) also yielded the similar results. Their results showed BMI and body image score were significantly linearly related - with higher body mass indicating more negative body image.

It can then be safely said that one major contributor to body image is the satisfaction a person has with the shape and relative weight of their body. A healthy weight-for-height ratio appears to be related to positive body image.

Studies on gender, BMI and body image showed varied results on the relationship, effects and interaction of gender, body mass index and body image.

Spanish studies by Rovira et.al. (2002) showed that there are differences between body mass index and subjective measures of physical measurements between girls and boys. Girls tend to overestimate their height and overestimate their weight than do boys. It appears logical then that girls tend to undergo restrictive dietary measures when they consider themselves overweight.
Other studies (Bogt et.al.) support similar results as in another study among Dutch youths, adolescent girls are more dissatisfied with their weight than boys; however, the relationship between weight perception and problem behavior is the same for both genders.

While the study of Roseblum and Lewis (2003), reported that bodily dissatisfaction increases among girls and decreases among boys. The same study shows that body dissatisfaction was weakly related their body mass index. However, it has also shown that when body image is developed in the adolescent years, they remain steady through much of adolescence.

This study answers the following research questions?

1. What is the effect of gender to body image?

2. What $s$ the effect of body mass index to body image?

3. Is there a significant interaction between gender and body mass index to body image?

The hypotheses tested for this research are as follows:

H1: Gender has an effect on body image regardless of body mass index.

H2: Body mass index has a significant effect on body image regardless of gender.

H3: The effect of gender on body image depends on body mass index.

This present study then addresses gender differences in body image and body mass index among adolescents. The results of this present study have practical implications for promoting positive body image among adolescents.

\section{RESEARCH DESIGN AND METHODS}

This study employed the cross-sectional research design where data from research participants were collected at a single point in time. The respondents of this study were 60 collegefreshmen undergraduate students. Simple random sampling was used in this study. Researchers decided to draw freshmen undergraduate students, 16 to 18 years old as sample to this study recognizing that adolescence is a time of rapid and intense emotional and physical changes and that body image and related self-concept emerge as significant factors associated with well-being during this developmental phase. Respondents below 18 years old were asked for their written assent and their guardians' written consent. Informed consent was sought from respondents 18 years old and older. The risks involved in this research are minimal. As survey research, 60 respondents was adapted as sample size: This is based on convention that maximum sample size is usually $10 \%$ of the population as long as it does not exceed 1000.

In this study, body image is defined as, "the picture of our own body which we form in our mind" was measured using the Body Image survey. This measure solicits for the respondent's gender and the respondent's height (in feet, inches) and his or her weight (in pounds). These were used as reference factors for body mass index. 
The Body Image Test (Jade, n.d.) elicits the respondents their degree of discomfort related to appearance in different situations e.g. in social gatherings.Responses will range from "never," scored as 0; "sometimes," scored as 1; "often," scored as 2; and "always," scored as 4 . High scores of 40 to 80 suggests very high dissatisfaction with body and appearance, scores 30 to 40 suggests poor body image, low scores of 10-20 suggest some degree of comfort with one's body and appearance, while 0 to 10 scores indicate a positive body image and self-esteem.

Body mass index is statistical measurement, which compares a person's weight and height. It does not actually measure the percentage of body fat but is is a useful tool to estimate a healthy body weight based on his or her height.. The English formula for computing body mass index is as follows:(Weight in Pounds /( Height in inches ) x ( Height in inches ) $) 703$

In this study, body mass index was generated by an online BMI calculator using respondents' self-reported approximate height and weight.

Respondents whose body mass index fall between 18.5 to 24.9 are considered normal, while those with less than 18.5 is considered underweight and with more than 25.0 is considered overweight. Underweight and overweight respondents were collectively onsidered in this study as nonnormal.

To investigate the effects of gender and body mass and their interaction effects to body image, two-way analysis of variance was used. The two-way analysis of variance was used in this study to analyze the difference between the means of more than two groups, male and female

\section{RESULTS}

This study examined the effect of gender to body image; the effect of body mass index to body image; and the interaction between gender and body mass index to body image.

Table 1: The Main Effect of Gender

\begin{tabular}{|l|l|l|l|}
\hline \multirow{2}{*}{ Gender } & \multicolumn{3}{|l|}{ Body mass index } \\
\cline { 2 - 4 } & normal & non normal & Average \\
\hline male & 16.40 & 17.13 & 16.77 \\
\hline female & 23.07 & 21.73 & 22.40 \\
\hline
\end{tabular}

The table above shows that male respondents have mean body image $16.77(S D=11.90)$ This suggests that males appear to be reasonably comfortable with and are satisfied with their physiques. This readily translates into positive body image and confidence. The female respondents on the other hand, have mean score of $22.40(S D=8.577)$. They report that they are not comfortable with their bodies and are not satisfied with their current physical appearance. In turn, this also reflected in their negative body image and esteem.

Respondents with normal body mass index (18.5 to 24.90) and those with non-normal (less than 18.5 and more than 25)
BMIs reported comparable mean scores of body, 19.73 $(S D=9.432)$ and $19.43(S D=12.031)$ respectively, suggesting a similar level of body confidence and satisfaction.

Table 3: the effect of gender to body image

\begin{tabular}{|c|c|c|c|}
\hline Source & $d f$ & $F$ & $p$ \\
\hline Gender & 1 & 4.24 & $.044^{*}$ \\
\hline Gender & 1 & .012 & .913 \\
\hline $\begin{array}{c}\text { Gender x Body Mass } \\
\text { Index }\end{array}$ & 1 & .143 & .707 \\
\hline
\end{tabular}

Dependent Variable: Body Image

This study examined the effect of gender to body image.

The results supported the hypothesis that gender has an effect on body image regardless of body mass index. The two-way analysis of variance yielded a main effect for gender, $F(1,56)$ $=4.241, p<.05$ such that females $(M=22.40, S D=8.577)$ have significantly higher body image scores, suggesting dissatisfaction of body, than did the male respondents $(M=$ $16.77, S D=11.990$ ) respondents. This was small difference with Cohen's effect .07. This suggests that female respondents are significantly less comfortable of their bodies than their male counterparts.

The present study also examined the effect of body mass index to body image. The results did not support the hypothesis that body mass index has a significant effect on body image regardless of gender. The main effect of body mass index was non-significant $F(1,56)=.012$ with $p>.05$ Normal $(M=19.73, S D=9.432)$ and non-normal $(M=19.43$, $S D=12.031)$ respondents have comparable levels of body satisfaction. Both normal and non-normal respondents appear to be comfortable and are satisfied with their bodies.

Additionally, this study did not support the hypothesis on the effect of gender on body image depends on body mass index. The interaction effect was non-significant $F(1,56) .143, p=$ .707. Male and female respondents with either normal or nonnormal body mass index do not differ significantly in their body image.

\section{DISCUSSION}

This study addressed the following research questions: the effect of gender to body image; the effect of body mass index to body image; and the interaction between gender and body mass index to body image.

On the effect of gender to body image, the results have shown that female respondents are less comfortable with their bodies than their male counterparts. Women generally have higher levels of body dissatisfaction than men. In general, women often report of wanting to lose weight, whereas men often report of want to build more muscle (Grogan, 2016). This recent study is consistent with the results of a earlier study which showed that body dissatisfaction exists in women across the life span and is influenced by body mass 
index(Runfola, VonHolle, Trace, Brownley, Hofmeier, Gagne, \& Bulik, 2013).

Social comparison theory (Festinger, 1954) explains the body dissatisfaction among females respondents. Body dissatisfaction can develop among females when they frequently compare their physical appearance to the appearance of others (Keery, Van den Berg, \& Thompson, 2004).

Presently, there are relatively more references to the females and the female body in the mass media, particularly in products and services that claim to reduce body fat, facilitate weight loss and endow the appropriate body shape. Moreover, the respondents are in the age range (i.e., teenage years), socioeconomic status (i.e., upper middle to upper class), geographic location (i.e., urban capital zone) that predisposes them to maximum exposure to media from every source, particularly from those heavily influenced with postmodern Western cultures. Studies have shown that there is a stronger relationship between body image and social comparison among females than with males. In addition it has also been found that women who compare themselves with other women - including models, celebrities and other images that mass media projects as ideals for females to strive for-are likely to be more dissatisfied with their body image.

Findings of a research showed females to be more dissatisfied with their current body shape in relation to their perception of men's ideals for the female form. Furthermore, researches revealed that body dissatisfaction increases among girls and decreases among boys, though there is more pressure placed on females to seek the ideal body shape prescribed by society. As a result, women usually want to be thinner than their present size, which in turn leads to dissatisfaction with their bodies.

The findings of these researches, which were mostly conducted in Western societies-because of media proliferation, and certain universal elements of gender archetypes - may be widely applicable among the female respondents of this study. (Cohn \& Adler, 1992). Other studies support that the frequent engaging in appearance comparisons is associated with high level of body dissatisfaction among women (Myers \&Crowther, 2009; Vartanian \& Dey, 2013).

On the effect of body mass index on the effect of body image, this study showed that body mass index was not found to have an effect on body image.

The results of this present study is contrary to the results of previous studies such as that of Watkins, Christie, and Chally (2008) which showed that body mass index was significantly correlated with negative body image. Similarly,the study of Watkins, Christie, and Chally (2008) reported that BMI was significantly correlated with negative body image: participants with heavier weights reported higher levels of negative body image, weight and shape concerns than their normal-weight counterparts. Generally, studies have shown a negative correlation between image and body mass index.

The result of this present study is inconsistent with the results of other studies such as those mentioned above. A number of reasons could be cited for why body mass index was not found to have an effect on body image.

In this study, the participants' weight and height were selfreported. It is then possible that participants may have inaccurately identified themselves in their self-report of weight and height. For example, Gorber, Tremblay, Moher, and Gorber (2007), showed that their data showed tendency to under-report weight and body mass index, and over-report height. This trend of over-reporting weight and underreporting height has been shown to vary between men and women. Additionally, the results of the same study had demonstrated substantial individual variability as has been shown by standard deviations.

Inaccuracy in weight and height self-reports of had also been demonstrated by Avila-Funes, Gutierrez-Robledo, \& de LeonRosales (2004) have shown a substantial difference between self-reported height and measured height. Self-reported height was over-estimated and the bias increased with age; and that over-estimation was evident in women than in men.

Another area to explore as to why body mass index was not found to have an effect on body image is to examine body mass index as an anthropometric measure. BMI is presently considered as the current basis of classification system for obesity. As in other anthropometric measure, it is an alternate measure of body fatness. Prentice and Jebb (2001)proposed that attention may be directed to development of standards based on direct body measurement rather than substitute measures.

It may then be possible that the BMI utilized in this study as anthropomorphic measure, may not be the suitable tool as it measures the relationship between height and weight. Issues concerning the use of BMI relates to its inability to yield a valid estimate of body percentage fat.

Another issue relates to gender differences in BMI readings even with given same percentage of fat. Inaccurate BMI readings may also come from muscle content of body. Alternate measures to BMI include waist circumference measurement and waist-to-hip ratio. Waist circumference measurement is determining natural waist and is a suitable indication of abdominal fat. Waist-to-hip ratio calculates excess wait as well as indicates vulnerability to health issues. Both alternates measures, waist circumference and waist-tohip ratio, may be used in future research to examine their effects on body image.

It may then be said that weight status, whether objective or perceived, could be related to body image. Future studies can attempt to examine the effects of weight status to body image among adolescents. 
With regards to gender and body mass index, both had not been found to affect body image. One possible explanation for this finding is that apart from gender and body mass index, they may be other influences on body image of adolescents. For example, the media which targets adolescents, influence adolescent body image. Research suggests that exposure to mass media which depicts ideal body is related to body image disturbance in women (Grabe, Ward, \& Hyde, 2008).Previous studies also indicate that exposure to thin-andbeautiful media images had adverse influence on the body image of adolescents as they tended to internalize the media standards of beauty and attractiveness .Future studies may also examine the role of media in the shaping of body image.

Peers have also been shown to shape one's body image. Jones (2001) confirmed that same-sex peers are targets of social comparison for physical, personal and social attributes. Among their peers, there is pressure to conform to what social is prescribed as body ideal.

The finding that gender and body mass index do not affect body image point to other psychological factors that contribute to the development of of body image of adolescents. Two have been consistently named in literature: media and peers. Specifically, the internalization of standards of physical attractiveness set by the media and conformity to peer pressure (McCabe, \& Ricciardelli, 2001).

To sum, the present study have shown that gender has a significant effect on the body image of college freshmen and sophomore psychology students at the Ateneo de Manila University, where the females are more considerably uncomfortable with their bodies than their male classmates. However, the body mass index or BMI has no significant effect on their body image and that the interaction of gender and BMI has no considerable effect on the body image of the freshmen and sophomore students at Ateneo de Manila University.

Adolescence has been identified as a period of identity development, part of which is the development of body image. Adolescent girls with strong interpersonal identity have shown to have more positive attitudes on other's perception of their physical appearance. Similarly, adolescent boys with strong interpersonal identity have also shown to consider their physical appearance positively (Voelker, Reel, \& Greenleaf, 2015).

\section{CONCLUSION}

This study addressed the following research issues: the effect of gender to body image; the effect of body mass index to body image; and the interaction between gender and body mass index to body image.The findings of this present study showed that gender has an effect on body image; that body mass index has no effect on body image; and that interaction between gender and body mass index to body image is not found.
The results of this study suggest that female college studentsare more predisposed to developing body dissatisfaction than their male counterparts. University counselors have be more on the lookout for indicators odof eating disorders and severe dieting among their female student counselees, regardless of body type or size. It is suggested that programs may be put in place to enhance positive bodyesteem among adolescents. Body-esteem programs may focus on promoting positive body image, characterized by a functional and accepting attitude one one's body. Body positive programs may include activities that encourage adolescents to think of their bodies as functional, active and useful. This is to veer away from the view that bodies are decorative and hence objectified. Adolescent body positive programs may also include examining the current ideals of beauty and how these standards apply to reality. In all, this study shows the importance of teaching, helping, and supporting adolescents to develop functional and accepting views of their bodies.

For future research, alternate anthropomorphic measures may be used to gauge physical qualities. Measures such as waist circumference and waist-to-hip ratio may be considered in the study of relationships of body qualities and body image. Future studies can also examine the effects of weight status, not only the body mass index. Because literature points to media representation of what is physically attractive and peer pressure as influencing adolescent body image, future studies may also examine both phenomenon in relation to the development of body image in adolescents.

\section{REFERENCES}

[1] Ata, R. N., Ludden, A. B., \&Lally, M. M. (2007). The effects of gender and family, friend, and media influences on eating behaviors and body image during adolescence. Journal of Youth and Adolescence, 36(8), 1024-1037.

[2] Brumberg, J. J. (1997). The Body project: An intimate history of American girls. NY: Random House.

[3] Cash, T. F., \& Deagle, E. A. (1997). The nature and extent of body-image disturbances in anorexia nervosa and bulimia nervosa: A meta-analysis. International Journal of Eating Disorders, 22, 107-125.

[4] Cash, T. F., \& Szymanski, M. L. (1995). The development and validation of the Body-image Ideals Questionnaire.Journal of Personality Assessment, 64, 466-477.

[5] Cohn, L.D. \& Adler, N.E. (1992). Female and male perceptions of ideal body shapes. Psychology of Women Quarterly, 16, 69-79.

[6] Cusumano, D. L., \& Thompson, J. K. (1997). Body image and body shape ideals in magazines: Exposures, awareness, and internalization. Sex Roles, 37 701--721.

[7] Davison, T. E., \& McCabe, M. P. (2006). Adolescent body image and psychosocial functioning. The Journal of social psychology, 146(1), 15-30

[8] Fisher, E., Dunn, M., \& Thompson, J. K. (2002). Social comparison and body image: An investigation of body comparison processes using multidimensional scaling. Journal of Social and Clinical Psychology, 21(5), 566-579.

[9] Garner, D.M., Garfinkel, P.E., Schwartz, D. \& Thompson, M. (1980). Cultural expectations of thinness in women. Psychological Reports

[10] Gorber, S. C., Tremblay, M., Moher, D., \&Gorber, B. (2007). A comparison of direct vs. self-report measures for assessing height, 
weight and body mass index: a systematic review. Obesity reviews, 8(4), 307-326.

[11] Grabe, S., Ward, L. M., \& Hyde, J. S. (2008). The role of the media in body image concerns among women: a meta-analysis of experimental and correlational studies. Psychological bulletin, 134(3), 460.

[12] Grogan, S. (2016). Body image: Understanding body dissatisfaction in men, women and children. Routledge.

[13] Hargreaves, D. (2002). Idealized Women in TV Ads Make Girls Feel Bad.Journal of Social and Clinical Psychology, 21, 287-308.

[14] Harrison, K. and Cantor, J. (1997). The relationship between media consumption and eating disorders.Journal of Communication, 47, 40-67.

[15] Jones, D. C. (2001). Social comparison and body image: Attractiveness comparisons to models and peers among adolescent girls and boys. Sex roles, 45(9), 645-664.

[16] Keery, H., Van den Berg, P., \& Thompson, J. K. (2004). An evaluation of the Tripartite Influence Model of body dissatisfaction and eating disturbance with adolescent girls. Body image, 1(3), 237-251.

[17] McCabe, M. P., \&Ricciardelli, L. A. (2001). Parent, peer, and media influences on body image and strategies to both increase and decrease body size among adolescent boys and girls. Adolescence, 36(142), 225.

[18] Morrison, T. G., Kalin, R., \& Morrison, M. A. (2004). Bodyimage evaluation and body-image investment among adolescents: A test of sociocultural and social comparison theories. Adolescence, 39(155), 571.

[19] Myers, T. A., \&Crowther, J. H. (2009). Social comparison as a predictor of body dissatisfaction: A meta-analytic review.

[20] Pinkasavage, E., Arigo, D., \& Schumacher, L. M. (2015). Social comparison, negative body image, and disordered eating behavior: the moderating role of coping style. Eating behaviors, 16, 72-77.

[21] Prentice, A. M., \&Jebb, S. A. (2001). Beyond body mass index. Obesity reviews, 2(3), 141-147

[22] Rosenblum, G. D., \& Lewis, M. (1999). The relations among body image, physical attractiveness, and body mass in adolescence. Child development,70(1), 50-64.
[23] RosauraFarréRovira, Isabel Frasquet Pons, Maria Isabel MartínezMartínez, Raquel Romá Sánchez. Self-Reported versus Measured Height, Weight and Body Mass Index in Spanish Mediterranean Teenagers: Effects of Gender, Age and Weight on Perceptual Measures of Body Image. Annals of Nutrition \& Metabolism 2002

[24] Runfola, C. D., Von Holle, A., Trace, S. E., Brownley, K. A., Hofmeier, S. M., Gagne, D. A., \&Bulik, C. M. (2013). Body dissatisfaction in women across the lifespan: Results of the UNC-SELF and gender and body image (GABI) studies. European Eating Disorders Review, 21(1), 52-59.

[25] Suls, J., \& Wheeler, L. (Eds.). (2013). Handbook of social comparison: Theory and research. Springer Science \& Business Media.

[26] van den Berg, P., \& Thompson, J. K. (2007). Self-schema and social comparison explanations of body dissatisfaction: A laboratory investigation.Body Image, 4(1), 29-38.

[27] Vartanian, L. R., \&Dey, S. (2013). Self-concept clarity, thin-ideal internalization, and appearance-related social comparison as predictors of body dissatisfaction. Body Image, 10(4), 495-500.

[28] Voelker, D. K., Reel, J. J., \& Greenleaf, C. (2015). Weight status and body image perceptions in adolescents: current perspectives. Adolescent health, medicine and therapeutics, 6 , 149.

[29] Watkins, J. A., Christie, C., \&Chally, P. (2008). Relationship between body image and body mass index in college men. Journal of American College Health, 57(1), 95-100.

[30] Yamamiya, Y., Cash, T. F., Melnyk, S. E., Posavac, H. D., \&Posavac, S. S. (2005). Women's exposure to thin-and-beautiful media images: Body image effects of media-ideal internalization and impact-reduction interventions.Body image, 2(1), 74-80.

[31] Gianine D. Rosenblum, Michael Lewis. Child Development. 2003 Watkins, Julia A (JA); Christie, Catherine (C); Chally, Pamela (P).Journal of American college health. 2008

[32] (n.d.) Retrieved http://www2.netdoctor.co.uk/testyoursf/facts/body_image.asp

[33] (n.d.) Retrieved from https://www/hhs.gov/ohrp/regulations-andpolicy/regulations/45-cfr-46 


\section{APPENDIX A:}

Body Image Survey

Please mark the circle corresponding to your rating for each item.

\begin{tabular}{|c|c|c|c|c|}
\hline $\begin{array}{c}\text { I feel uncomfortable about my } \\
\text { appearance... }\end{array}$ & & & & \\
\hline & never & $\begin{array}{l}\text { someti } \\
\text { mes }\end{array}$ & often & always \\
\hline $\begin{array}{l}\text { At social gatherings where I know } \\
\text { few people }\end{array}$ & o & o & o & o \\
\hline When I look at myself in the mirror & o & o & o & o \\
\hline When I am with attractive people & o & o & o & o \\
\hline $\begin{array}{l}\text { When someone looks at parts of my } \\
\text { appearance that I dislike }\end{array}$ & o & o & o & o \\
\hline When I try on new clothes & o & o & o & o \\
\hline When I exercise & o & o & o & o \\
\hline After I have eaten a full meal & o & o & o & o \\
\hline When I am wearing revealing clothes & o & o & $\mathrm{o}$ & o \\
\hline $\begin{array}{c}\text { When I get on the scale to weigh } \\
\text { myself }\end{array}$ & o & o & o & o \\
\hline $\begin{array}{l}\text { When I think someone has rejected } \\
\text { me }\end{array}$ & o & o & o & o \\
\hline When I am in romantic situation & o & o & o & o \\
\hline When I am in a bad mood & o & o & o & o \\
\hline $\begin{array}{l}\text { When I think about how I looked } \\
\text { when I was younger }\end{array}$ & o & o & o & o \\
\hline $\begin{array}{l}\text { When I see myself in a photo or on } \\
\text { video }\end{array}$ & o & o & o & o \\
\hline When I think I've gained weight & o & o & o & o \\
\hline $\begin{array}{l}\text { When I think about what I wished I } \\
\text { looked like }\end{array}$ & o & o & o & o \\
\hline $\begin{array}{l}\text { When I recall hurtful things people } \\
\text { have said about my appearance }\end{array}$ & o & o & o & o \\
\hline $\begin{array}{l}\text { When I am with people who talk } \\
\text { about weight or dieting }\end{array}$ & o & o & o & o \\
\hline When I look at fashion magazines & o & o & o & o \\
\hline When I think about going on holiday & o & o & o & o \\
\hline & & & & \\
\hline
\end{tabular}

Age:

Gender:

Male

Female

Approximate Height (in ft.):

Approximate Weight (in lbs.): 